\title{
Material Identification Using Dual Energy X-ray Absorptiometry
}

October 2021

Dongwon Lee

Lawrence-Livermore National Laboratory

Zachary J. Thompson

Idaho National Laboratory

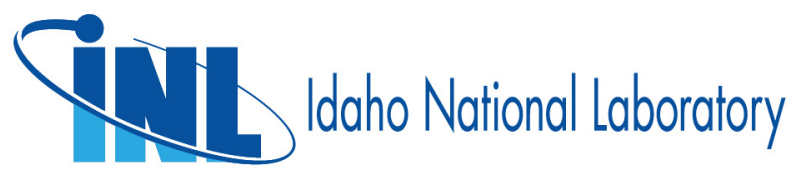

INL is a U.S. Department of Energy National Laboratory

operated by Battelle Energy Alliance, LLC 


\section{DISCLAIMER}

This information was prepared as an account of work sponsored by an agency of the U.S. Government. Neither the U.S. Government nor any agency thereof, nor any of their employees, makes any warranty, expressed or implied, or assumes any legal liability or responsibility for the accuracy, completeness, or usefulness, of any information, apparatus, product, or process disclosed, or represents that its use would not infringe privately owned rights. References herein to any specific commercial product, process, or service by trade name, trade mark, manufacturer, or otherwise, does not necessarily constitute or imply its endorsement, recommendation, or favoring by the U.S. Government or any agency thereof. The views and opinions of authors expressed herein do not necessarily state or reflect those of the U.S. Government or any agency thereof. 
INL/EXT-21-64717

Revision 000

\title{
Material Identification Using Dual Energy X-ray Absorptiometry
}

\author{
Dongwon Lee \\ Lawrence-Livermore National Laboratory \\ Zachary J. Thompson \\ Idaho National Laboratory
}

October 2021

Idaho National Laboratory
Idaho Falls, Idaho 83415

http://www.inl.gov

Prepared for the Project Manager

Recovered Chemical Materiel Directorate, United States Army

Under DOE Idaho Operations Office

Contract DE-AC07-05ID14517 
Page intentionally left blank 


\begin{abstract}
Two implementations of dual energy X-ray absorptiometry were studied to identify materials using X-ray attenuation data taken with the Digital Radiography and Computed Tomography (DRCT) systems that were developed for the Recovered Chemical Materiel Directorate (RCMD). Maitrejean et al.'s approach utilizes eigen effects through Principal Component Analysis, while Osipov et al.'s approach proposed a physics-based method. Both approaches approximate mass attenuation coefficients of materials as a linear combination of basis functions (eigen effects) or physics-based equations. A set of coefficients $\left\{a_{1}, a_{2}, a_{3}\right\}$ or $\{B, D\}$ were found by parameter optimization in EXCEL Solver. The identification parameters, $\left\{\frac{a_{2}}{a_{1}}, \frac{a_{3}}{a_{1}}\right\}$ or estimated effective atomic number $\hat{Z}$ from $\{B, D\}$, were calculated to identify material of an aluminum 8 step wedge and a steel 8 step wedge in X-ray radiography images taken by a DRCT system. Maitrejean et al.'s approach was unable to provide reliable $\frac{a_{3}}{a_{1}}$ ratio values for identification of materials. Osipov et al.'s approach was found to be more robust in identify materials with a semi-empirical formula derived from test results in this study.
\end{abstract}


Page intentionally left blank 


\section{CONTENTS}

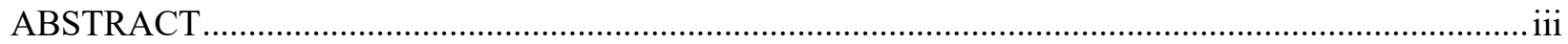

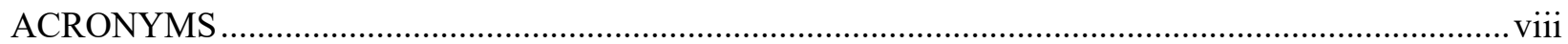

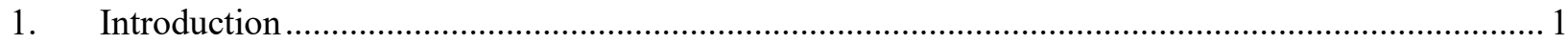

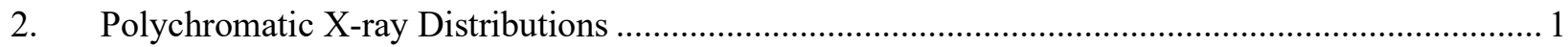

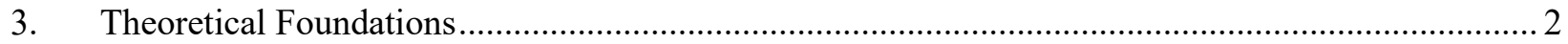

3.1 Eigen Effects Approach by Maitrejean et al. ..................................................................... 2

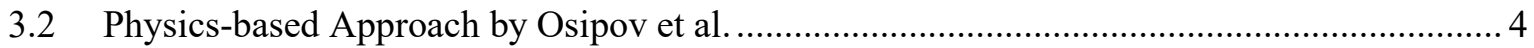

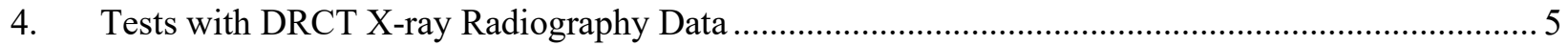

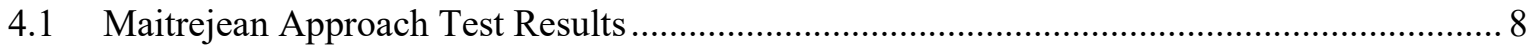

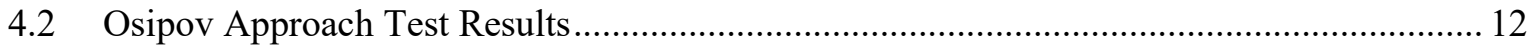

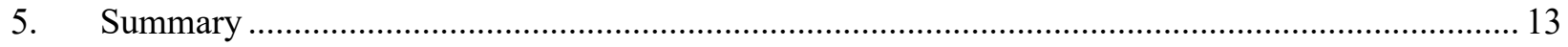

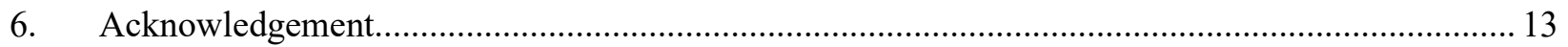

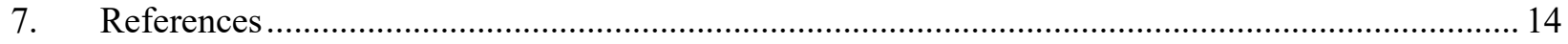

Appendix A EXCEL Spreadsheet for Parameter Optimization .............................................................. 16

\section{FIGURES}

Figure 1. Normalized X-ray distributions for various X-ray tube voltages. ........................................... 2

Figure 2. NIST XCOM mass-attenuation data for materials. ................................................................. 3

Figure 3. The three basis functions for PCA as a function of photon energy........................................... 4

Figure 4. A comparison of NIST XCOM data the functions governing attenuation in [2] for

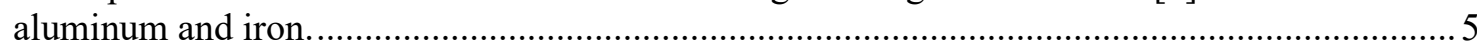

Figure 5. An example X-ray DR image of step wedges (left) and example traces through the aluminum step wedge at the two exposure settings (right). The vertical line on the image denotes the approximate location of the data.

Figure 6. An example X-ray DR image of step wedges (left) and example traces through the steel step wedge at the two exposure settings (right). The vertical line on the image denotes the approximate location of the data

Figure 7. A 2-D scatter plot of identification parameters $\{a 2 a 1, a 3 a 1\}$ obtained from four step wedge data sets along with those from NIST XCOM data.....

Figure 8. A 2-D scatter plot of $a 2 a 1$ vs effective atomic number obtained from four step wedge data sets along with those from NIST XCOM data. A polynomial fit and corresponding equation are also included.

Figure 9. Estimated effective atomic numbers for aluminum $(\mathrm{Al})$ and steel $(\mathrm{Fe})$...

Figure 10. Estimated effective atomic numbers for aluminum (Al) and steel (Fe) when using free parameters. 
Figure 11. EXCEL spreadsheet for Maitrejean el al.'s approach ......................................................... 18

Figure 12. EXCEL spreadsheet for Osipov el al.'s approach. .............................................................. 19

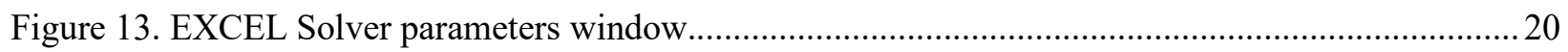

\section{TABLES}

Table 1. Identification parameters for 18 of the 20 key elements........................................................ 8

Table 2. optimal coefficients $\{a 1, a 2, a 3\}$ and their corresponding identification parameters $\{a 2 a 1, a 3 a 1\}$ for each step on four step wedge data sets. ................................................. 10

Table 3. Table of effective atomic numbers for each step on four step wedge data sets.......................... 11 
Page intentionally left blank 


\section{ACRONYMS}

CT Computed Tomography

DR Digital Radiograph

DRCT Digital Radiography and Computed Tomography

DRCT SMS Digital Radiography and Computed Tomography Single Munition Scanner

INL Idaho National Laboratory

IQI Image Quality Indicator

LDA Linear Diode Array

NIST National Institute for Standards and Technology

PCA Principal Component Analysis

PENELOPE Penetration and Energy Loss of Positrons and Electrons

RCMD Recovered Chemical Materiel Directorate

SLSQP Sequential Least Squares Quadratic Programming

SSR Sum of Squared Residuals

SVD Single Value Decomposition

XRG X-ray Generator 
Page intentionally left blank 


\section{Material Identification Using Dual Energy X-ray Absorptiometry}

\section{Introduction}

Multi-energy X-ray absorptiometry has been commonly used to estimate quantitative material properties of test objects [1-2]. Maitrejean et al. introduced a pair of identification parameters to classify test materials according to their parameters [1] and Osipov et al. proposed a physics-based approach to calculate the estimated effective atomic number [2]. Both approaches were developed to extract meaningful X-ray attenuation information from digital radiographs (DRs) when using polychromatic Xray spectra of various energy (voltage) settings. This study was conducted to investigate feasibility of incorporating these two approaches into Digital Radiography and Computed Tomography (DRCT) systems at Idaho National Laboratory (INL) with the ultimate goal of demonstrating the effectiveness of both approaches with X-ray DR data from fielded DRCT systems, primarily the DRCT Single Munition Scanner (DRCT SMS). Aluminum and steel step wedges were the primary test objects for identification by their estimated effective atomic numbers using Osipov et al.'s approach and by their identification parameters using Maitrejean et al.'s approach.

\section{Polychromatic X-ray Distributions}

Accurate models of polychromatic X-ray distributions at various voltage (energy) settings are critically important for identify materials. Directly measuring X-ray distributions generated by X-ray generators (XRGs) used on DRCT systems would be the ideal course of action for characterization. However, this is technically challenging, and energy resolved X-ray detectors have only recently been realized and were not available for this study. To overcome this obstacle, the linear diode array (LDA) detector response function must be well characterized. Instead of measuring X-ray distributions, simulations were used to synthesize polychromatic X-ray spectra at different voltage (energy) settings. It is important to note that $\mathrm{X}$-ray tube voltage is proportional to the maximum photon energy emitted from the XRG. To clarify, an XRG operating at $300 \mathrm{kV}$ can produce X-ray photons up to $300 \mathrm{keV}$. X-ray distributions for this study were modeled using data obtained from the XRG manufacturer (target material and target angle) in a pyPENELOPE (Python implementation of PENELOPE, Penetration and ENErgy LOss of Positrons and Electrons) simulation. The X-ray distribution leaving the target in the XRG and passing through the inherent filtering materials for a given maximum energy $E_{k}$ (tube voltage) was calculated using the Beer-Lambert law as $\phi\left(E, E_{k}\right)$. Next the emitted X-ray distribution, $\phi\left(E, E_{k}\right)$, passes through the object. The emitted distribution is attenuated by the object and is denoted as $\phi_{\text {transmitted }}\left(E, E_{k}\right)$. Finally, the detector response, $\varepsilon(E)$, which was compiled through a comprehensive 
literature review, is multiplied by $\phi_{\text {transmitted }}\left(E, E_{k}\right)$. The product of $\varepsilon(E)$ and $\phi_{\text {transmitted }}\left(E, E_{k}\right)$ served as the effective X-ray spectrum $\varphi\left(E, E_{k}\right)$ throughout this study. The $E_{k}$ value was varied from 175 $\mathrm{kV}(k=1)$ to $300 \mathrm{kV}(k=6)$ in increments of $25 \mathrm{kV}$. Figure 1 shows the effective X-ray spectra of 6 different voltage settings. It should be noted that X-ray distributions only from $50 \mathrm{keV}$ to $300 \mathrm{keV}$ in increments of $1 \mathrm{keV}$ were used because counts below $50 \mathrm{keV}$ were insignificant and contributions to the recorded counts in the detector array were considered negligible. Also, all X-ray spectra were normalized to meet the condition

$$
\int_{0}^{E_{k}} \varphi\left(E, E_{k}\right) d E=1
$$

This normalization was intended to simplify numerical calculations throughout this study.

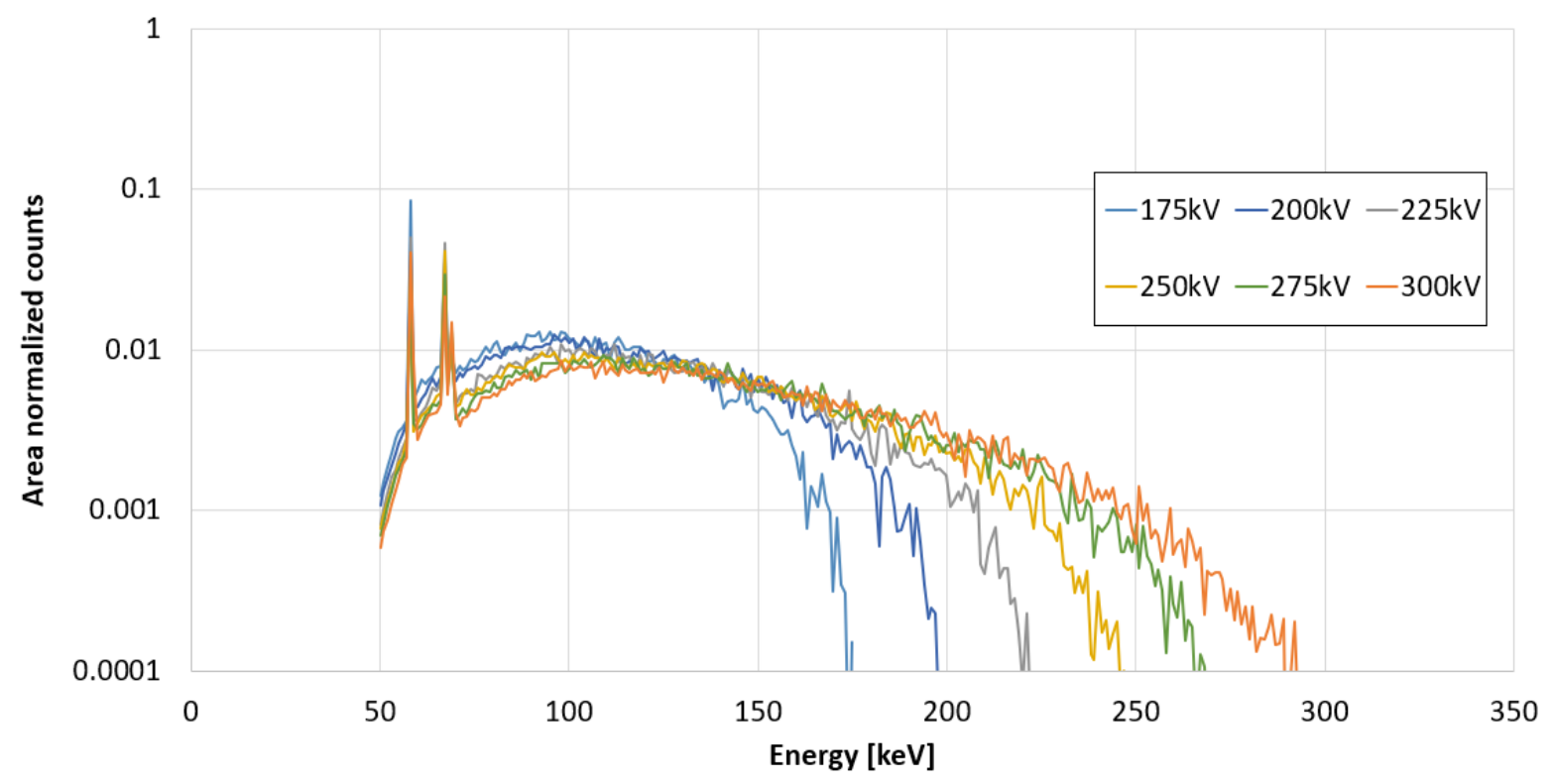

Figure 1. Normalized X-ray distributions for various X-ray tube voltages.

\section{Theoretical Foundations}

\subsection{Eigen Effects Approach by Maitrejean et al.}

The eigen effects approach by Maitrejean et al. has been proposed on the theoretical foundations of Principal Component Analysis (PCA) [3]. This approach has demonstrated that mass attenuation coefficients of matter could be approximated by a linear combination of basis functions $\boldsymbol{u}_{\boldsymbol{i}}$ (eigen effects).

$$
\left(\frac{\mu(E)}{\rho}\right) H \approx \sum_{i} a_{i} \boldsymbol{u}_{i}
$$

where $\mathrm{H}$ is mass thickness (density $\times$ thickness). A pair of identification parameters derived from $a_{i}$, $\left\{\frac{a_{2}}{a_{1}}, \frac{a_{3}}{a_{1}}\right\}$, were considered unique to a material while independent of thickness by taking ratios according 
to the reference work. Therefore, it is essential to find basis functions before finding $a_{i}$ with experimental attenuation data. First, mass attenuation coefficients of 20 key elements were obtained from the National Institute for Standards and Technology (NIST) XCOM database [4]. In order to be consistent with the energy resolution of $1 \mathrm{keV}$ of X-ray spectra, mass attenuation coefficients were tabulated from $50 \mathrm{keV}$ to $300 \mathrm{keV}$ in increments of $1 \mathrm{keV}$. Figure 2 shows the NIST XCOM data used in this study. As a result, a $20 \times 251$ matrix $\boldsymbol{M}$ of mass attenuation coefficients was processed through PCA to find basis functions. A loading matrix $\boldsymbol{U}$ is found from the covariance matrix of $\boldsymbol{M}$ by

$$
\operatorname{cov}(\boldsymbol{M})=\boldsymbol{U} \boldsymbol{\Lambda} \boldsymbol{U}^{T}
$$

This process can be done by applying Single Value Decomposition (SVD) to the covariance matrix of $\boldsymbol{M}$, and the magnitude of each diagonal element of the matrix $\boldsymbol{\Lambda}$ indicates the importance of the corresponding basis function. PCA results showed that the first three basis functions, the first three column vectors of $\boldsymbol{U}$, would be enough to approximate mass attenuation coefficients. The first three basis functions from PCA results are shown in Figure 3 (page 4).

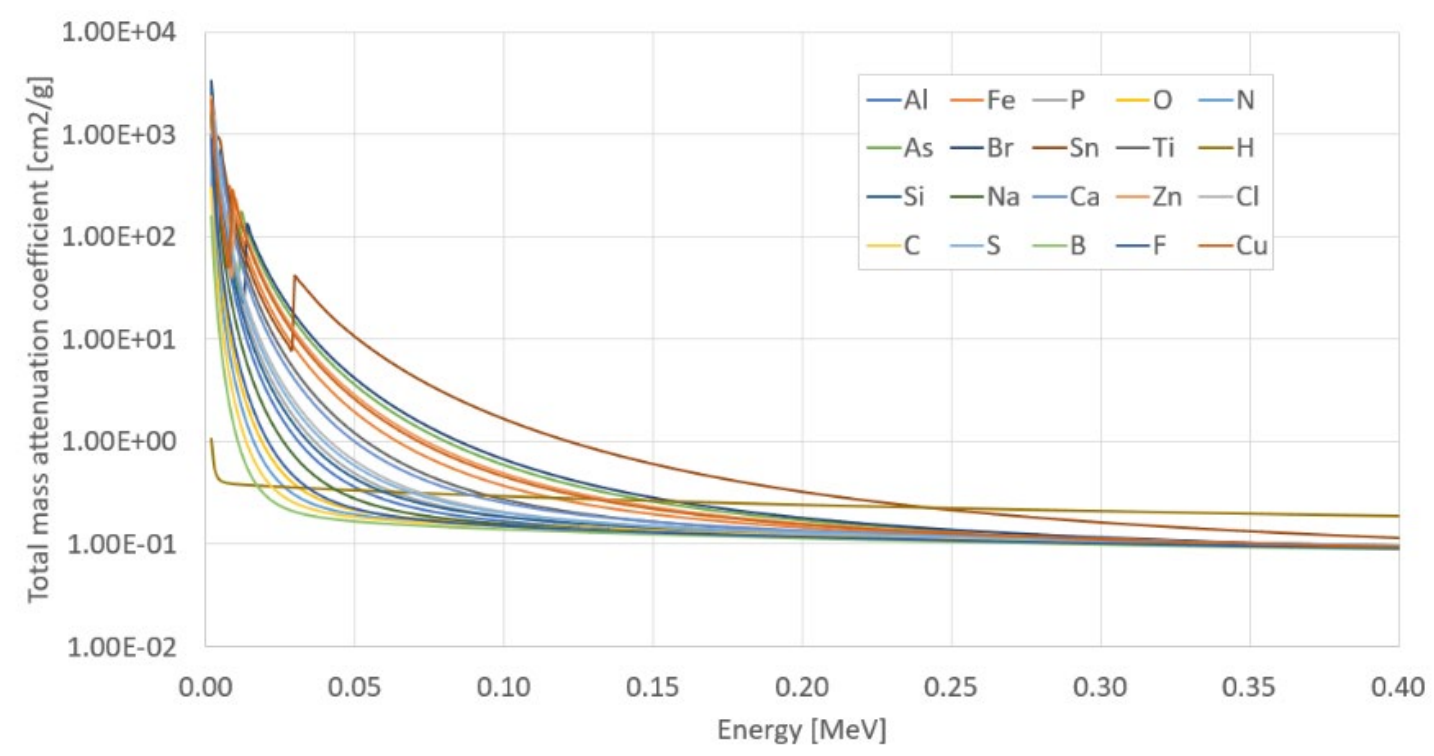

Figure 2. NIST XCOM mass-attenuation data for materials. 


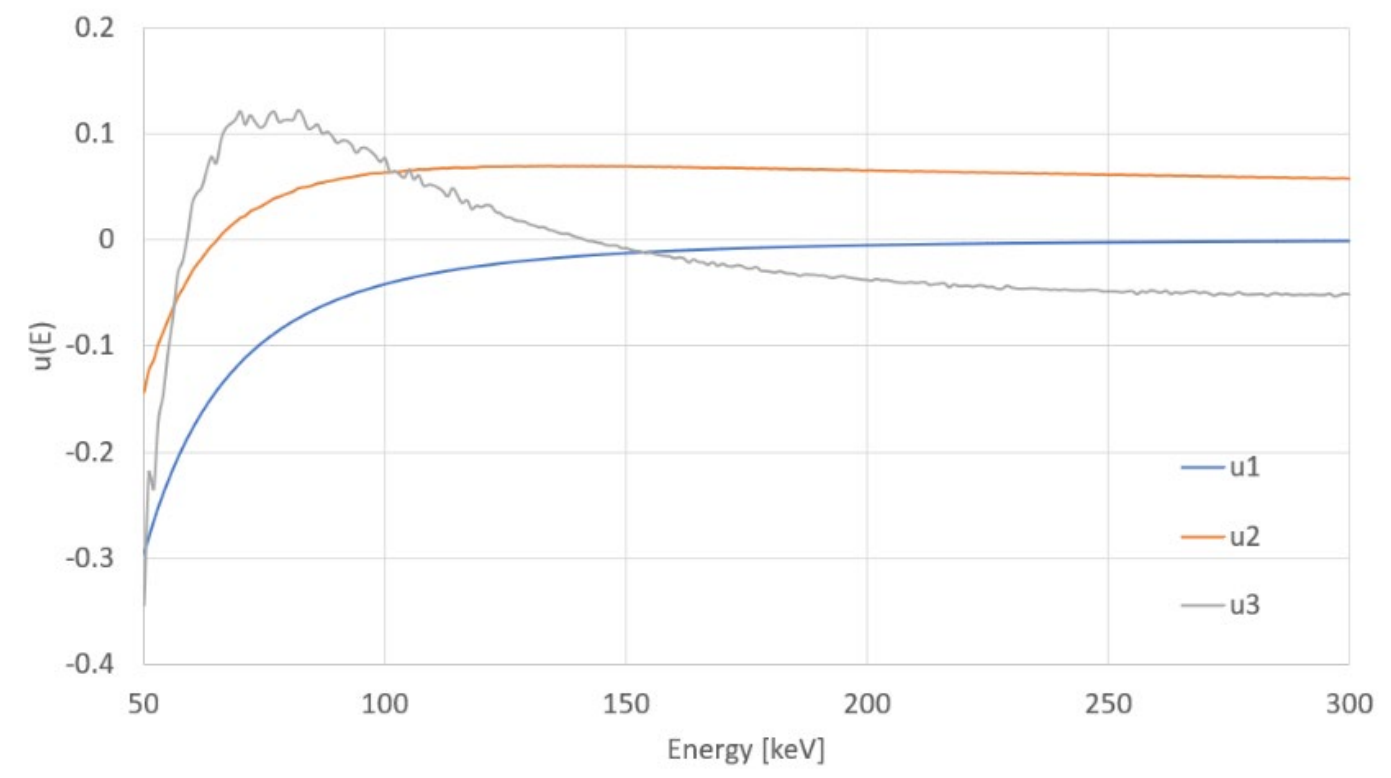

Figure 3. The three basis functions for PCA as a function of photon energy.

\subsection{Physics-based Approach by Osipov et al.}

Osipov et al. demonstrated that mass attenuation coefficients of materials could be represented by sum of photoelectric effect and incoherent scattering (Compton scattering) in the following form:

$$
\left(\frac{\mu(E)}{\rho}\right) H \approx B f_{p h}(E)+D f_{K N}(E)
$$

Equations for $B, D, f_{p h}(E)$ and $f_{K N}(E)$ are given by Equation (10) through (24) in the reference by Osipov et al. [2], and the equation to calculate the estimated effective atomic number $\hat{Z}$ in general is given by

$$
\hat{Z}=0.457^{3.8} \sqrt{\frac{B}{D}}
$$

The ratio of $B$ to $D$ both carry information of mass thickness $H$ so their ratio, $\frac{B}{D}$, becomes independent of material thickness. Figure 4 shows $B f_{p h}(E)$ and $D f_{K N}(E)$ by the equations in Osipov et al. for aluminum and iron along with NIST XCOM data, respectively. 

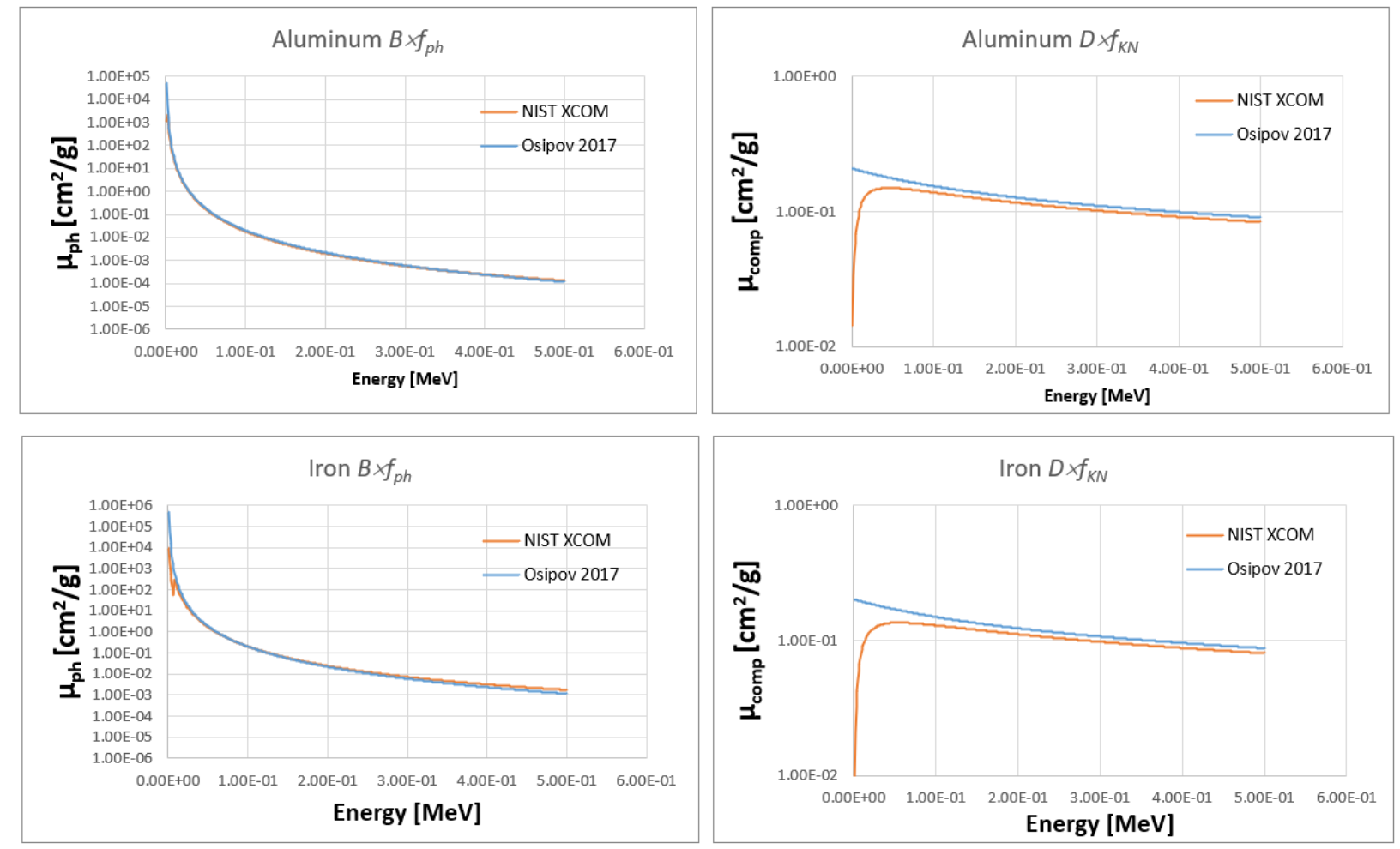

Figure 4. A comparison of NIST XCOM data the functions governing attenuation in [2] for aluminum and iron.

\section{Tests with DRCT X-ray Radiography Data}

"Effective coefficients of radiation transmittance" was adopted from Osipov et al. to find coefficients $\left\{a_{1}, a_{2}, a_{3}\right\}$ and $\{B, D\}$ from multi-energy (multi-voltage) X-ray DRCT data. For the two approaches, effective coefficients of radiation transmittance for a given maximum photon energy $E_{k}$ and mass thickness $\mathrm{H}$ are given by

$$
\begin{gathered}
d_{k}(H) \approx \frac{\int_{0}^{E_{k}} \varphi\left(E, E_{k}\right) \exp ^{-\left(\frac{\mu(E)}{\rho}\right) H} d E}{\int_{0}^{E_{k}} \varphi\left(E, E_{k}\right) d E}=\frac{\int_{0}^{E_{k}} \varphi\left(E, E_{k}\right) \exp ^{-\sum_{i} a_{i} u_{i}} d E}{\int_{0}^{E_{k}} \varphi\left(E, E_{k}\right) d E}=\hat{d}_{k}(H) \quad \text { and } \\
d_{k}(H) \approx \frac{\int_{0}^{E_{k}} \varphi\left(E, E_{k}\right) \exp ^{-\left(\frac{\mu(E)}{\rho}\right) H} d E}{\int_{0}^{E_{k}} \varphi\left(E, E_{k}\right) d E}=\frac{\int_{0}^{E_{k}} \varphi\left(E, E_{k}\right) \exp ^{-B f_{p h}(E)-D f_{K N}(E)} d E}{\int_{0}^{E_{k}} \varphi\left(E, E_{k}\right) d E}=\hat{d}_{k}(H),
\end{gathered}
$$

respectively. Where $\varphi\left(E, E_{k}\right)$ is the effective X-ray spectrum discussed in Section 2, and the denominators in both Equation (6) and (7) are equal to 1 as all X-ray spectra were normalized as laid out in Equation (1). The left side of the Equation (6) and (7) were obtained from the measurements with various X-ray voltage settings and mass thicknesses by

$$
d_{k}(H)=\frac{N_{k}(H)}{N_{k}(0)}
$$


where $N_{k}(0)$ and $N_{k}(H)$ are the total recorded counts without and with an object of mass thickness $H$, respectively. It is worth noting that $d_{k}(H)$ is colloquially known as the measured relative integrated power transmission in other areas of imaging physics and optics. For an object with the same thickness, the $d_{k}$ values from transmission measurements at the various X-ray tube voltage (energy) settings were compared to $\hat{d}_{k}$ in order to find the coefficients $\left\{a_{1}, a_{2}, a_{3}\right\}$ or $\{B, D\}$ in one of the following ways. The first was employed in the initial excel implementation and minimized the sum of squared residuals (SSR).

$$
S S R=\sum_{k}\left(d_{k}-\hat{d}_{k}\right)^{2}
$$

The second method minimizes using a sequential least squares quadratic programming (SLSQP) algorithm. In general, the procedure using DRCT data can be summarized in the following manner: multiple $d_{k}$ values from the measurements are obtained by Equation (8) for an object at the same thickness (i.e. the same step on the step wedge). Next, a set of coefficients $\left\{a_{1}, a_{2}, a_{3}\right\}$ or $\{B, D\}$ is numerically found when the SSR or SLSQP is minimized. Finally, identification parameters, $\left\{\frac{a_{2}}{a_{1}}, \frac{a_{3}}{a_{1}}\right\}$, or effective atomic number, $\hat{Z}$, is calculated to deduce the object's material composition.

With the theoretical foundations laid out in Section 3, an EXCEL spreadsheet was set up to perform the procedure described above SSR minimization for each approach. Shortly afterward, a Python script was developed using SLSQP minimization for future full image implementation. Next, a collection of DRCT X-ray DR data of aluminum and steel step wedges were used to test algorithms implemented in Excel and Python. The left side of Figure 5 shows a typical X-ray DR image of step wedges taken by a DRCT SMS, and it is clearly shown that the total recorded counts of the step wedges are governed by Xray attenuation through different thicknesses. Note that two DR images were taking at different exposure setting, leading to the two traces seen on the right side of Figure 5 and Figure 6. 

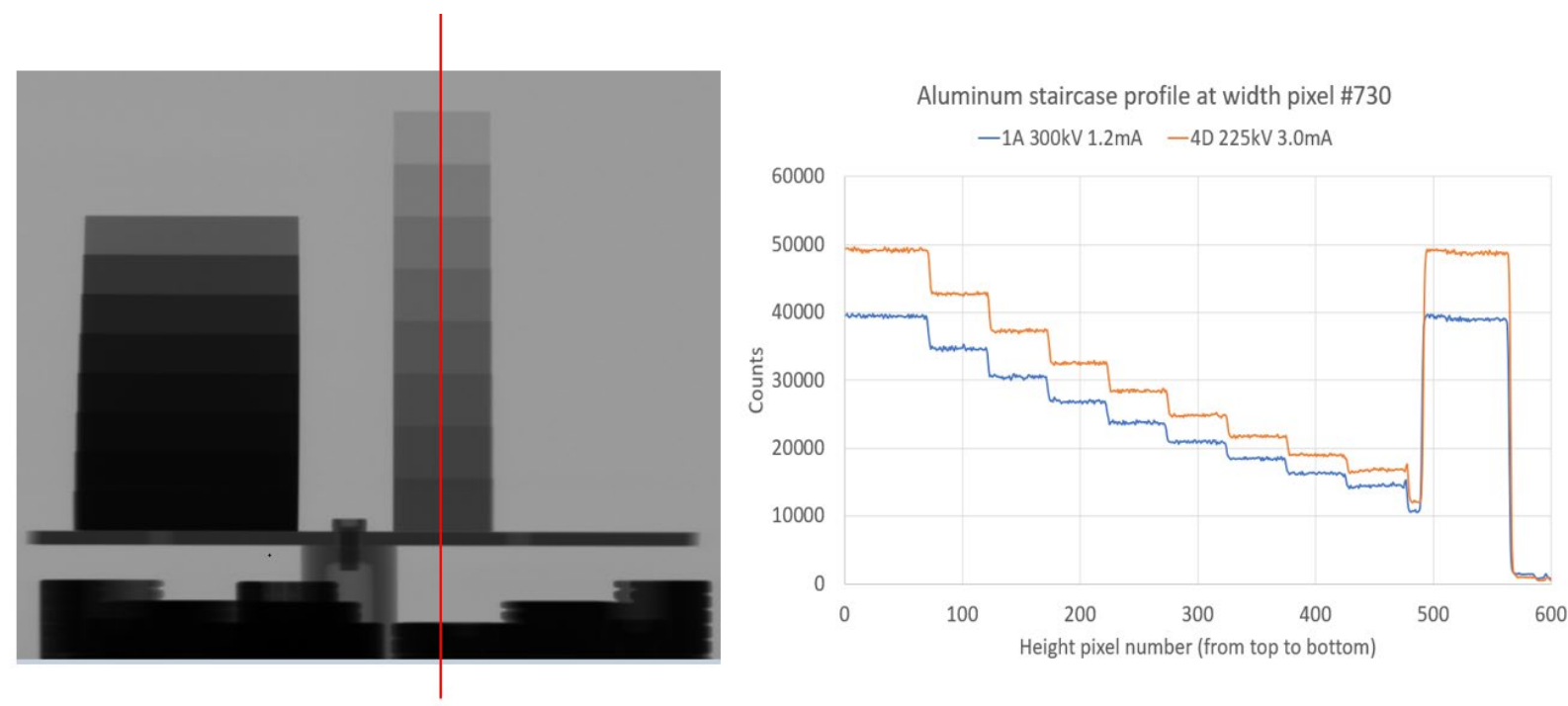

Figure 5. An example X-ray DR image of step wedges (left) and example traces through the aluminum step wedge at the two exposure settings (right). The vertical line on the image denotes the approximate location of the data.
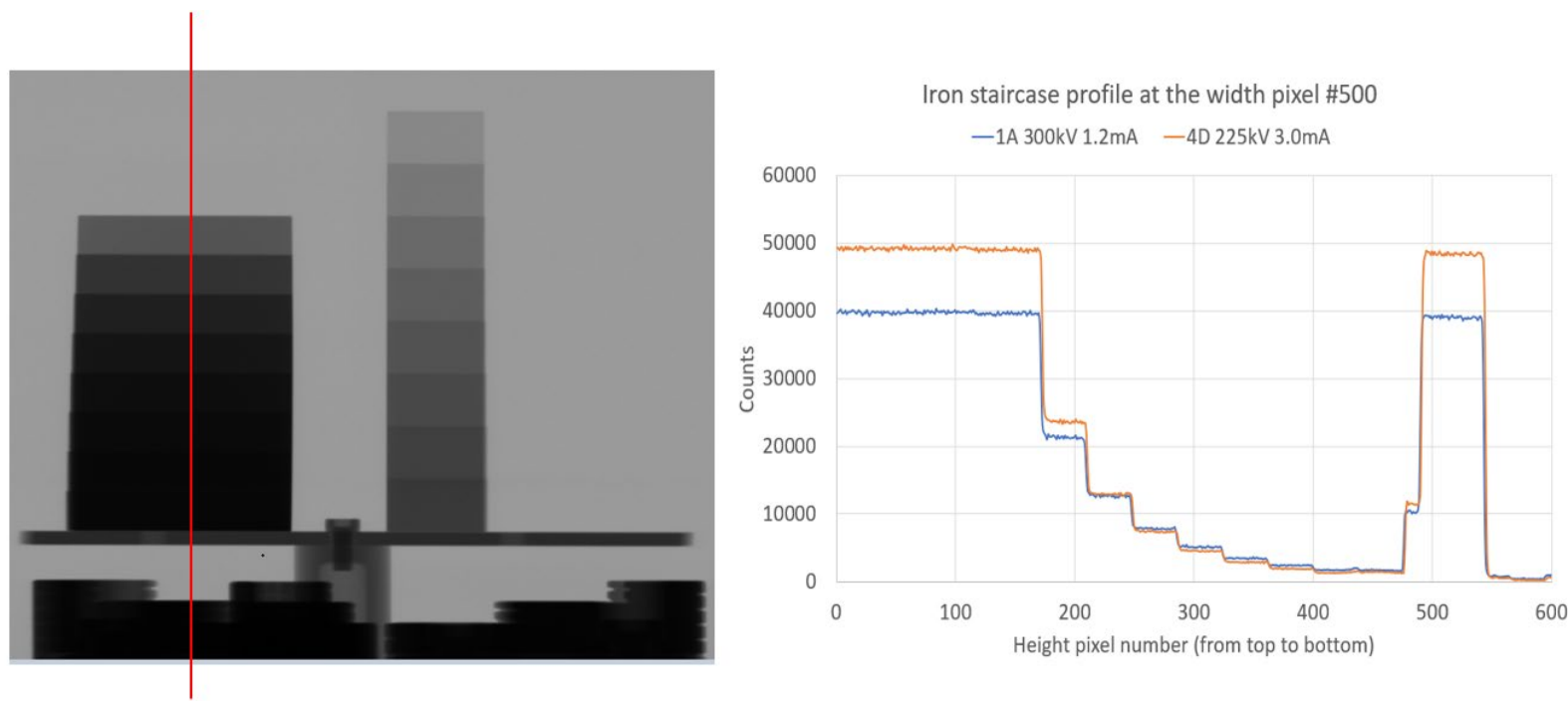

Figure 6. An example X-ray DR image of step wedges (left) and example traces through the steel step wedge at the two exposure settings (right). The vertical line on the image denotes the approximate location of the data.

$N_{k}(0)$ and $N_{k}(H)$ from an X-ray DR image of aluminum and steel step wedge for the maximum energy (voltage) setting $E_{k}$ are extracted from the image's average pixel values inside small areas centered above the wedges (airshot) and around the centers of the steps as shown in Figure 5 and Figure 6. Ideally, $\left\{\frac{a_{2}}{a_{1}}, \frac{a_{3}}{a_{1}}\right\}$ or $\hat{Z}$ for a given material should converge to its material specific values, i.e. $\hat{Z} \cong 13$ for aluminum and $\hat{Z} \cong 26$ for steel, regardless of mass thickness values. When $d_{k}$ values for each step from the data are 
entered in the EXCEL spreadsheet, $\hat{d}_{k}$ values are repeatedly calculated by varying and optimizing a set of coefficients $\left\{a_{1}, a_{2}, a_{3}\right\}$ or $\{B, D\}$. The optimal set of $\left\{a_{1}, a_{2}, a_{3}\right\}$ or $\{B, D\}$ are found when the SSR value in Equation (9) reaches the minimum value. It should be noted, however, that there are multiple local minima and the solution might not be the global minimum. Therefore, it is very important to start EXCEL solver with the best possible initial guess values for $\left\{a_{1}, a_{2}, a_{3}\right\}$ or $\{B, D\}$. Next, $\left\{\frac{a_{2}}{a_{1}}, \frac{a_{3}}{a_{1}}\right\}$ or $\hat{Z}$ is calculated with the optimal set of coefficients $\left\{a_{1}, a_{2}, a_{3}\right\}$ or $\{B, D\}$. Appendix $\mathrm{A}$ is an instruction for the EXCEL spreadsheets written for the two approaches.

\begin{tabular}{|c|c|c|c|c|c|c|}
\hline Element & $\mathrm{Z}$ & $\mathrm{a} 1$ & $\mathrm{a} 2$ & $\mathrm{a} 3$ & $\mathrm{a} / \mathrm{a} 1$ & $\mathrm{a} / \mathrm{a} 1$ \\
\hline $\mathrm{H}$ & 1 & $-2.43 \mathrm{E}+00$ & $3.35 \mathrm{E}+00$ & $-2.84 \mathrm{E}-01$ & $-1.38 \mathrm{E}+00$ & $1.17 \mathrm{E}-01$ \\
\hline $\mathrm{B}$ & 5 & $-1.17 \mathrm{E}+00$ & $1.57 \mathrm{E}+00$ & $-1.32 \mathrm{E}-01$ & $-1.34 \mathrm{E}+00$ & $1.12 \mathrm{E}-01$ \\
\hline $\mathrm{C}$ & 6 & $-1.29 \mathrm{E}+00$ & $1.69 \mathrm{E}+00$ & $-1.43 \mathrm{E}-01$ & $-1.31 \mathrm{E}+00$ & $1.11 \mathrm{E}-01$ \\
\hline $\mathrm{N}$ & 7 & $-1.33 \mathrm{E}+00$ & $1.69 \mathrm{E}+00$ & $-1.43 \mathrm{E}-01$ & $-1.28 \mathrm{E}+00$ & $1.08 \mathrm{E}-01$ \\
\hline $\mathrm{O}$ & 8 & $-1.38 \mathrm{E}+00$ & $1.70 \mathrm{E}+00$ & $-1.44 \mathrm{E}-01$ & $-1.23 \mathrm{E}+00$ & $1.05 \mathrm{E}-01$ \\
\hline $\mathrm{F}$ & 9 & $-1.37 \mathrm{E}+00$ & $1.61 \mathrm{E}+00$ & $-1.38 \mathrm{E}-01$ & $-1.18 \mathrm{E}+00$ & $1.01 \mathrm{E}-01$ \\
\hline $\mathrm{Na}$ & 11 & $-1.57 \mathrm{E}+00$ & $1.62 \mathrm{E}+00$ & $-1.45 \mathrm{E}-01$ & $-1.04 \mathrm{E}+00$ & $9.25 \mathrm{E}-02$ \\
\hline $\mathrm{Al}$ & 13 & $-1.85 \mathrm{E}+00$ & $1.63 \mathrm{E}+00$ & $-1.55 \mathrm{E}-01$ & $-8.79 \mathrm{E}-01$ & $8.34 \mathrm{E}-02$ \\
\hline $\mathrm{Si}$ & 14 & $-2.11 \mathrm{E}+00$ & $1.68 \mathrm{E}+00$ & $-1.66 \mathrm{E}-01$ & $-8.00 \mathrm{E}-01$ & $7.88 \mathrm{E}-02$ \\
\hline $\mathrm{P}$ & 15 & $-2.26 \mathrm{E}+00$ & $1.63 \mathrm{E}+00$ & $-1.68 \mathrm{E}-01$ & $-7.23 \mathrm{E}-01$ & $7.43 \mathrm{E}-02$ \\
\hline $\mathrm{S}$ & 16 & $-2.58 \mathrm{E}+00$ & $1.68 \mathrm{E}+00$ & $-1.80 \mathrm{E}-01$ & $-6.50 \mathrm{E}-01$ & $6.99 \mathrm{E}-02$ \\
\hline $\mathrm{Cl}$ & 17 & $-2.76 \mathrm{E}+00$ & $1.61 \mathrm{E}+00$ & $-1.81 \mathrm{E}-01$ & $-5.83 \mathrm{E}-01$ & $6.58 \mathrm{E}-02$ \\
\hline $\mathrm{Ca}$ & 20 & $-3.99 \mathrm{E}+00$ & $1.66 \mathrm{E}+00$ & $-2.19 \mathrm{E}-01$ & $-4.14 \mathrm{E}-01$ & $5.47 \mathrm{E}-02$ \\
\hline $\mathrm{Ti}$ & 22 & $-4.58 \mathrm{E}+00$ & $1.51 \mathrm{E}+00$ & $-2.22 \mathrm{E}-01$ & $-3.30 \mathrm{E}-01$ & $4.85 \mathrm{E}-02$ \\
\hline $\mathrm{Fe}$ & 26 & $-7.04 \mathrm{E}+00$ & $1.51 \mathrm{E}+00$ & $-2.70 \mathrm{E}-01$ & $-2.15 \mathrm{E}-01$ & $3.84 \mathrm{E}-02$ \\
\hline $\mathrm{Cu}$ & 29 & $-9.20 \mathrm{E}+00$ & $1.48 \mathrm{E}+00$ & $-2.96 \mathrm{E}-01$ & $-1.60 \mathrm{E}-01$ & $3.22 \mathrm{E}-02$ \\
\hline $\mathrm{Zn}$ & 30 & $-1.01 \mathrm{E}+01$ & $1.48 \mathrm{E}+00$ & $-3.07 \mathrm{E}-01$ & $-1.46 \mathrm{E}-01$ & $3.02 \mathrm{E}-02$ \\
\hline $\mathrm{As}$ & 33 & $-1.26 \mathrm{E}+01$ & $1.43 \mathrm{E}+00$ & $-3.17 \mathrm{E}-01$ & $-1.14 \mathrm{E}-01$ & $2.51 \mathrm{E}-02$ \\
\hline $\mathrm{Br}$ & 35 & $-1.47 \mathrm{E}+01$ & $1.44 \mathrm{E}+00$ & $-3.25 \mathrm{E}-01$ & $-9.79 \mathrm{E}-02$ & $2.20 \mathrm{E}-02$ \\
\hline $\mathrm{Sn}$ & 50 & $-3.71 \mathrm{E}+01$ & $1.99 \mathrm{E}+00$ & $-4.86 \mathrm{E}-02$ & $-5.37 \mathrm{E}-02$ & $1.31 \mathrm{E}-03$ \\
\hline
\end{tabular}

Table 1. Identification parameters for 18 of the 20 key elements.

\subsection{Maitrejean Approach Test Results}

Table 1 shows the coefficients $\left\{a_{1}, a_{2}, a_{3}\right\}$ and their corresponding identification parameters $\left\{\frac{a_{2}}{a_{1}}, \frac{a_{3}}{a_{1}}\right\}$ for 18 of the 20 key elements. The coefficients $\left\{a_{1}, a_{2}, a_{3}\right\}$ of each element in Table 1 was found via fit to NIST XCOM data by Equation (2) and mass thickness $H$ was set to 1.0 for all elements. The identification parameters $\left\{\frac{a_{2}}{a_{1}}, \frac{a_{3}}{a_{1}}\right\}$ in Table 1 are considered reference values to be compared to those obtained from the measured data. Table 2 (page 10) summarizes the optimal coefficients $\left\{a_{1}, a_{2}, a_{3}\right\}$ and their corresponding identification parameters $\left\{\frac{a_{2}}{a_{1}}, \frac{a_{3}}{a_{1}}\right\}$ for each step on four sets of DRCT DR data: an 
aluminum 8-step wedge with two maximum energy (voltage) settings ( $E_{l}=225 \mathrm{kV}$ and $E_{2}=300 \mathrm{kV}$ ), a steel 8-step wedge with two maximum energy (voltage) settings $\left(E_{l}=225 \mathrm{kV}\right.$ and $\left.E_{2}=300 \mathrm{kV}\right)$, an aluminum 8-step wedge in an image quality indicator (IQI) with three maximum energy (voltage) settings $\left(E_{1}=225 \mathrm{kV}, E_{2}=300 \mathrm{kV}\right.$ and $\left.E_{3}=300 \mathrm{kV}\right)$, and a steel 8-step wedge with three maximum energy (voltage) settings $\left(E_{l}=225 \mathrm{kV}, E_{2}=300 \mathrm{kV}\right.$ and $\left.E_{3}=300 \mathrm{kV}\right)$. Figure 7 shows a 2-D scatter plot of identification parameters $\left\{\frac{a_{2}}{a_{1}}, \frac{a_{3}}{a_{1}}\right\}$ obtained from the four data sets along with those from NIST XCOM data. Figure 7 suggests that $\frac{a_{3}}{a_{1}}$ values are less reliable to be used for identifying materials while $\frac{a_{2}}{a_{1}}$ values are relatively closer to the results obtained from NIST XCOM data. A possible explanation is that $u_{3}$ may have a much smaller contribution to the mass attenuation coefficient so its fitted coefficients, $a_{3}$, are superfluous and not significant. Figure 8 shows $\frac{a_{2}}{a_{1}}$ values might be used to deduce the effective atomic number of materials, which is expressed as a polynomial function of $\frac{a_{2}}{a_{1}}$ on Figure 8 (page 11). Table 3 (page 11) summarizes the deduced effective atomic numbers of aluminum and steel 8-step wedges with the proposed polynomial function shown at the bottom in Figure 8 (page 11).

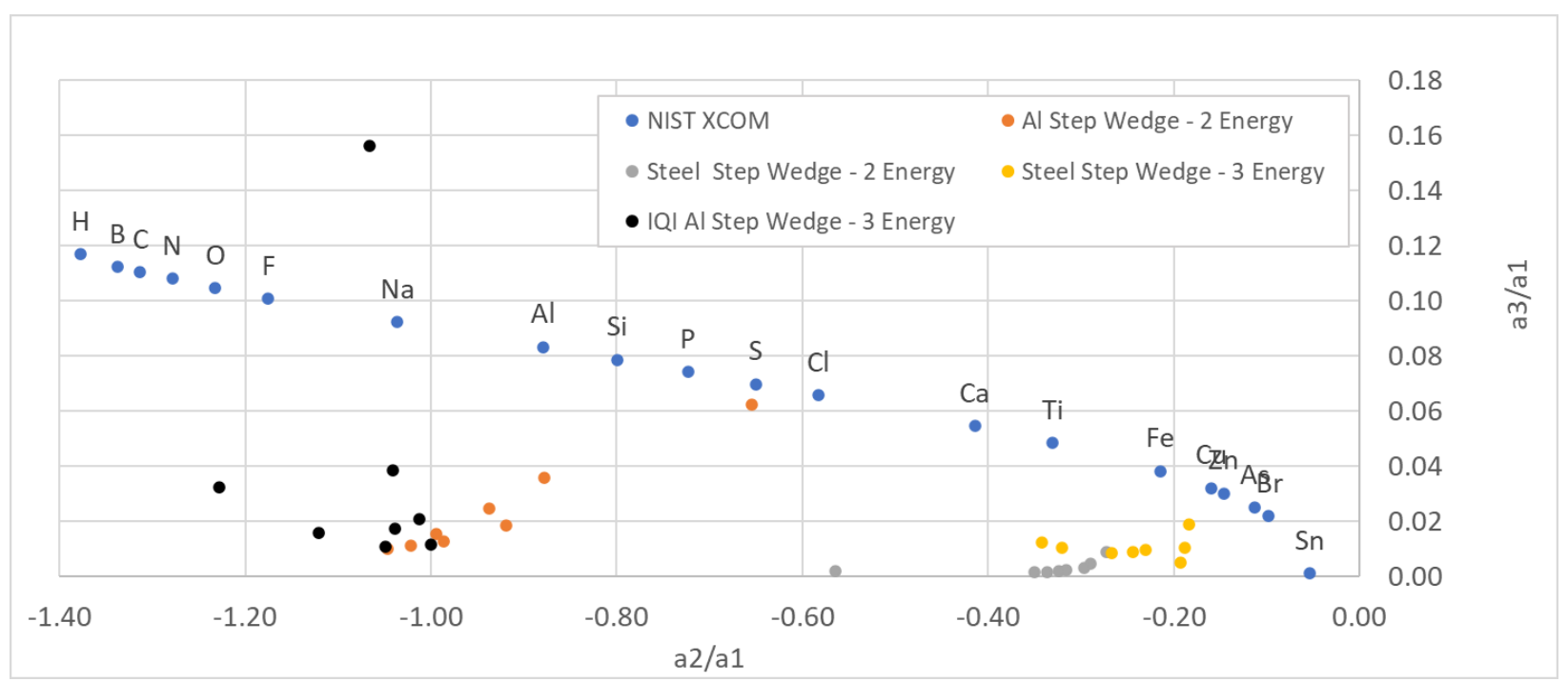

Figure 7. A 2-D scatter plot of identification parameters $\left\{\frac{a_{2}}{a_{1}}, \frac{a_{3}}{a_{1}}\right\}$ obtained from four step wedge data sets along with those from NIST XCOM data. 


\begin{tabular}{|c|c|c|c|c|c|c|}
\hline Data Set & $\begin{array}{c}\text { Step } \\
\text { Thickness }\end{array}$ & a1 & a2 & a3 & a2/a1 & a3/a1 \\
\hline \multirow{8}{*}{$\begin{array}{c}\text { Al Step Wedge - } 2 \\
\text { Energy }\end{array}$} & 0.125 & $-1.68 \mathrm{E}+00$ & $1.10 \mathrm{E}+00$ & $-1.05 E-01$ & $-6.55 \mathrm{E}-01$ & $6.26 \mathrm{E}-02$ \\
\hline & 0.250 & $-2.90 \mathrm{E}+00$ & $2.55 \mathrm{E}+00$ & $-1.05 E-01$ & $-8.78 \mathrm{E}-01$ & $3.61 \mathrm{E}-02$ \\
\hline & 0.375 & $-4.19 \mathrm{E}+00$ & $3.92 \mathrm{E}+00$ & $-1.04 \mathrm{E}-01$ & $-9.37 \mathrm{E}-01$ & $2.49 \mathrm{E}-02$ \\
\hline & 0.500 & $-5.61 E+00$ & $5.16 \mathrm{E}+00$ & $-1.04 \mathrm{E}-01$ & $-9.19 \mathrm{E}-01$ & $1.85 \mathrm{E}-02$ \\
\hline & 0.625 & $-6.73 E+00$ & $6.69 \mathrm{E}+00$ & $-1.04 \mathrm{E}-01$ & $-9.94 \mathrm{E}-01$ & $1.54 \mathrm{E}-02$ \\
\hline & 0.750 & $-8.12 E+00$ & $8.00 \mathrm{E}+00$ & $-1.04 \mathrm{E}-01$ & $-9.86 \mathrm{E}-01$ & $1.28 \mathrm{E}-02$ \\
\hline & 0.875 & $-9.28 \mathrm{E}+00$ & $9.48 \mathrm{E}+00$ & $-1.03 \mathrm{E}-01$ & $-1.02 \mathrm{E}+00$ & $1.11 \mathrm{E}-02$ \\
\hline & 1.000 & $-1.04 \mathrm{E}+01$ & $1.09 \mathrm{E}+01$ & $-1.03 E-01$ & $-1.05 E+00$ & $9.95 \mathrm{E}-03$ \\
\hline \multirow{8}{*}{$\begin{array}{c}\text { Steel Step Wedge - } \\
2 \text { Energy }\end{array}$} & 0.125 & $-1.28 \mathrm{E}+01$ & $3.50 \mathrm{E}+00$ & $-1.16 \mathrm{E}-01$ & $-2.73 E-01$ & 9.01E-03 \\
\hline & 0.250 & $-2.55 E+01$ & $7.40 \mathrm{E}+00$ & -1.17E-01 & $-2.90 \mathrm{E}-01$ & $4.58 \mathrm{E}-03$ \\
\hline & 0.375 & $-3.87 E+01$ & $1.15 \mathrm{E}+01$ & $-1.17 \mathrm{E}-01$ & $-2.96 \mathrm{E}-01$ & $3.02 \mathrm{E}-03$ \\
\hline & 0.500 & $-4.96 \mathrm{E}+01$ & $1.57 \mathrm{E}+01$ & $-1.17 \mathrm{E}-01$ & $-3.16 \mathrm{E}-01$ & $2.36 \mathrm{E}-03$ \\
\hline & 0.625 & $-6.06 \mathrm{E}+01$ & $1.96 \mathrm{E}+01$ & -1.17E-01 & $-3.24 \mathrm{E}-01$ & $1.93 \mathrm{E}-03$ \\
\hline & 0.750 & $-6.98 \mathrm{E}+01$ & $2.35 \mathrm{E}+01$ & $-1.17 \mathrm{E}-01$ & $-3.37 \mathrm{E}-01$ & $1.68 \mathrm{E}-03$ \\
\hline & 0.875 & $-7.79 E+01$ & $2.73 \mathrm{E}+01$ & $-1.17 \mathrm{E}-01$ & $-3.50 \mathrm{E}-01$ & $1.50 \mathrm{E}-03$ \\
\hline & 1.000 & $-5.49 E+01$ & $3.10 \mathrm{E}+01$ & $-1.17 \mathrm{E}-01$ & $-5.65 \mathrm{E}-01$ & $2.13 \mathrm{E}-03$ \\
\hline \multirow{8}{*}{$\begin{array}{c}\text { IQI Al Step Wedge - } \\
3 \text { Energy }\end{array}$} & 0.125 & $-2.62 E+00$ & $2.80 \mathrm{E}+00$ & $-4.11 \mathrm{E}-01$ & $-1.07 \mathrm{E}+00$ & $1.56 \mathrm{E}-01$ \\
\hline & 0.250 & $-3.81 E+00$ & $3.96 \mathrm{E}+00$ & $-1.47 \mathrm{E}-01$ & $-1.04 \mathrm{E}+00$ & 3.87E-02 \\
\hline & 0.375 & $-4.69 \mathrm{E}+00$ & $5.76 \mathrm{E}+00$ & $-1.52 \mathrm{E}-01$ & $-1.23 \mathrm{E}+00$ & $3.24 \mathrm{E}-02$ \\
\hline & 0.500 & $-6.57 E+00$ & $6.65 \mathrm{E}+00$ & $-1.36 \mathrm{E}-01$ & $-1.01 \mathrm{E}+00$ & 2.07E-02 \\
\hline & 0.625 & $-7.73 E+00$ & $8.03 E+00$ & $-1.35 E-01$ & $-1.04 \mathrm{E}+00$ & $1.74 \mathrm{E}-02$ \\
\hline & 0.750 & $-8.64 \mathrm{E}+00$ & $9.68 \mathrm{E}+00$ & $-1.39 \mathrm{E}-01$ & $-1.12 \mathrm{E}+00$ & 1.60E-02 \\
\hline & 0.875 & $-1.07 E+01$ & $1.07 \mathrm{E}+01$ & $-1.23 \mathrm{E}-01$ & $-1.00 \mathrm{E}+00$ & 1.15E-02 \\
\hline & 1.000 & $-1.15 \mathrm{E}+01$ & $1.21 \mathrm{E}+01$ & $-1.25 \mathrm{E}-01$ & $-1.05 \mathrm{E}+00$ & $1.08 \mathrm{E}-02$ \\
\hline \multirow{8}{*}{$\begin{array}{l}\text { Steel Step Wedge - } \\
3 \text { Energy }\end{array}$} & 0.125 & $-1.43 E+01$ & $2.62 \mathrm{E}+00$ & $-2.71 \mathrm{E}-01$ & $-1.84 \mathrm{E}-01$ & 1.90E-02 \\
\hline & 0.250 & $-3.03 E+01$ & $5.69 \mathrm{E}+00$ & $-3.17 \mathrm{E}-01$ & $-1.88 \mathrm{E}-01$ & $1.05 \mathrm{E}-02$ \\
\hline & 0.375 & $-4.32 E+01$ & $9.95 \mathrm{E}+00$ & $-4.15 E-01$ & $-2.30 \mathrm{E}-01$ & $9.61 \mathrm{E}-03$ \\
\hline & 0.500 & $-5.70 E+01$ & $1.39 \mathrm{E}+01$ & $-5.07 \mathrm{E}-01$ & $-2.45 \mathrm{E}-01$ & $8.90 \mathrm{E}-03$ \\
\hline & 0.625 & $-5.79 E+01$ & $1.98 \mathrm{E}+01$ & $-7.14 \mathrm{E}-01$ & $-3.42 \mathrm{E}-01$ & $1.23 \mathrm{E}-02$ \\
\hline & 0.750 & $-8.05 E+01$ & $2.15 E+01$ & $-7.00 \mathrm{E}-01$ & $-2.67 \mathrm{E}-01$ & 8.70E-03 \\
\hline & 0.875 & $-8.05 E+01$ & $2.58 \mathrm{E}+01$ & $-8.59 \mathrm{E}-01$ & $-3.20 \mathrm{E}-01$ & 1.07E-02 \\
\hline & 1.000 & $-1.22 \mathrm{E}+02$ & $2.35 \mathrm{E}+01$ & $-6.24 \mathrm{E}-01$ & $-1.93 \mathrm{E}-01$ & 5.11E-03 \\
\hline
\end{tabular}

Table 2. optimal coefficients $\left\{a_{1}, a_{2}, a_{3}\right\}$ and their corresponding identification parameters $\left\{\frac{a_{2}}{a_{1}}, \frac{a_{3}}{a_{1}}\right\}$ for each step on four step wedge data sets. 


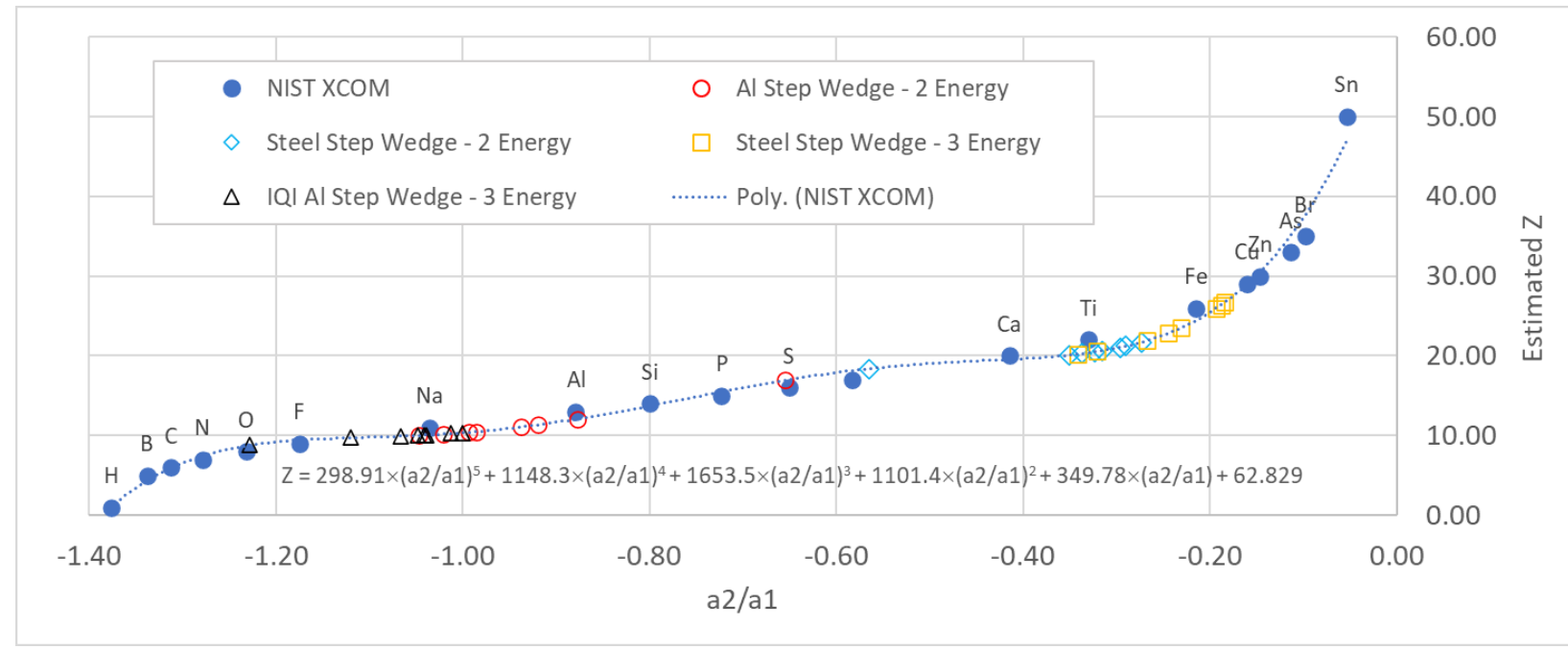

Figure 8. A 2-D scatter plot of $\frac{a_{2}}{a_{1}}$ vs effective atomic number obtained from four step wedge data sets along with those from NIST XCOM data. A polynomial fit and corresponding equation are also included.

\begin{tabular}{|c|c|c|c|c|}
\hline Step Thickness & $\begin{array}{c}\text { Al Step Wedge - 2 } \\
\text { Energy }\end{array}$ & $\begin{array}{c}\text { Steel Step Wedge } \\
\text { - 2 Energy }\end{array}$ & $\begin{array}{c}\text { IQI Al Step Wedge } \\
\text { - 3 Energy }\end{array}$ & $\begin{array}{c}\text { Steel Step Wedge } \\
\text { - 3 Energy }\end{array}$ \\
\hline 0.125 & 16.93 & 21.72 & 9.92 & 26.73 \\
\hline 0.250 & 12.06 & 21.20 & 10.04 & 26.38 \\
\hline 0.375 & 11.06 & 21.04 & 8.79 & 23.53 \\
\hline 0.500 & 11.33 & 20.62 & 10.23 & 22.82 \\
\hline 0.625 & 10.39 & 20.48 & 10.05 & 20.20 \\
\hline 0.750 & 10.47 & 20.27 & 9.71 & 21.90 \\
\hline 0.875 & 10.17 & 20.09 & 10.33 & 20.53 \\
\hline 1.000 & 10.01 & 18.38 & 10.00 & 25.99 \\
\hline Average & 11.55 & 20.48 & 9.89 & 23.51 \\
\hline
\end{tabular}

Table 3. Table of effective atomic numbers for each step on four step wedge data sets. 


\subsection{Osipov Approach Test Results}

In addition to the four DRCT data sets used in section 4.1, two more data sets were included: an aluminum 8-step wedge and a steel 8-step wedge with 6 different voltage settings $\left(E_{1}=175 \mathrm{kV}, E_{2}=200\right.$ $\mathrm{kV}, E_{3}=225 \mathrm{kV}, E_{4}=250 \mathrm{kV}, E_{5}=275 \mathrm{kV}$ and $E_{6}=300 \mathrm{kV}$ ). Figure 9 shows the estimated effective atomic numbers from the optimal coefficients $\{B, D\}$ of 6 data sets. Equation (5) was used to calculate $\hat{Z}$ when $\{B, D\}$ were found to minimize SSR. Test results show that the steel step wedge's $\hat{Z}$ values are underestimated while the aluminum step wedge's $\hat{Z}$ values are overestimated as observed in Figure 9.

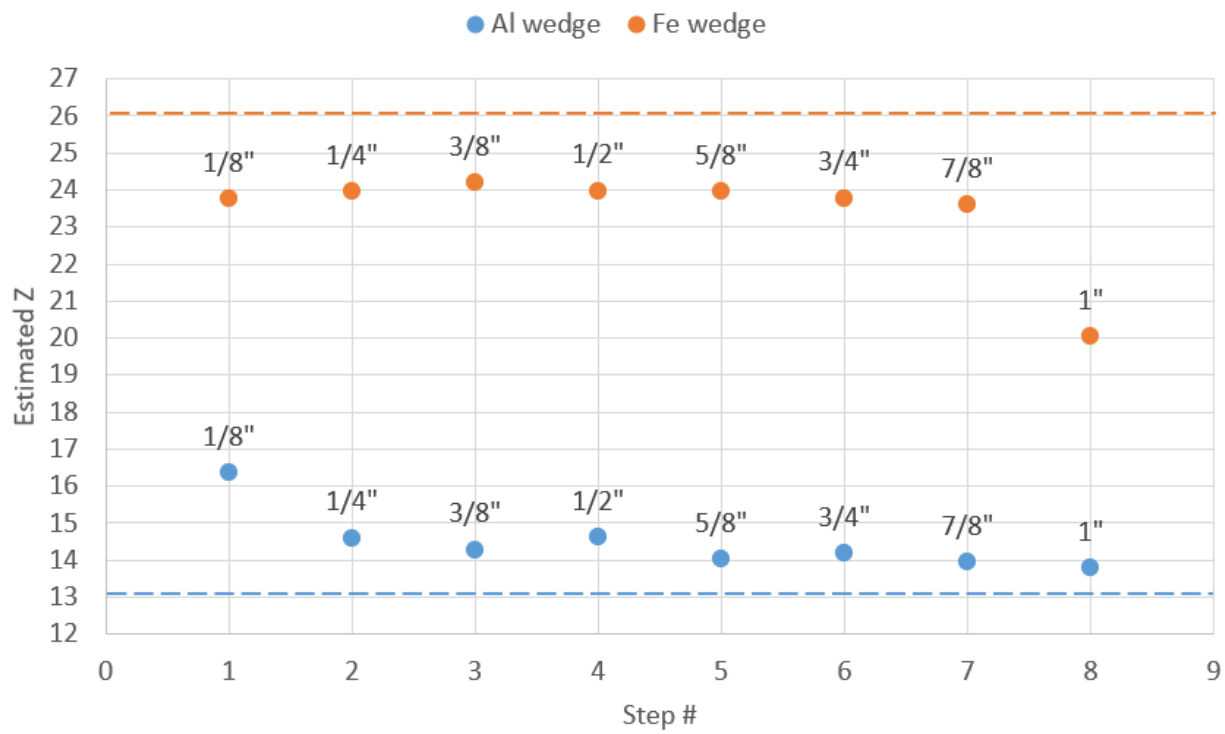

Figure 9. Estimated effective atomic numbers for aluminum $(\mathrm{Al})$ and steel $(\mathrm{Fe})$.

In order to improve the accuracy of the estimated $\hat{Z}$ values, Equation (5) was modified to have two free parameters: $\alpha$ (leading coefficient) and $\beta$ (root power).

$$
\hat{Z}=\alpha \sqrt[\beta]{\frac{B}{D}}
$$

Next, Equation (10) was fitted with a total of 6 data sets to find the best performing $\{\alpha, \beta\}$, and the updated results of the estimated $\hat{Z}$ values are shown in Figure 10 (page 13) when $\{\alpha, \beta\}$ is equal to $\{0.008865,3.17\}$. These two parameters are subject to change whenever new data sets are added and Equation (10) is fitted with the expanded collection of data sets. 


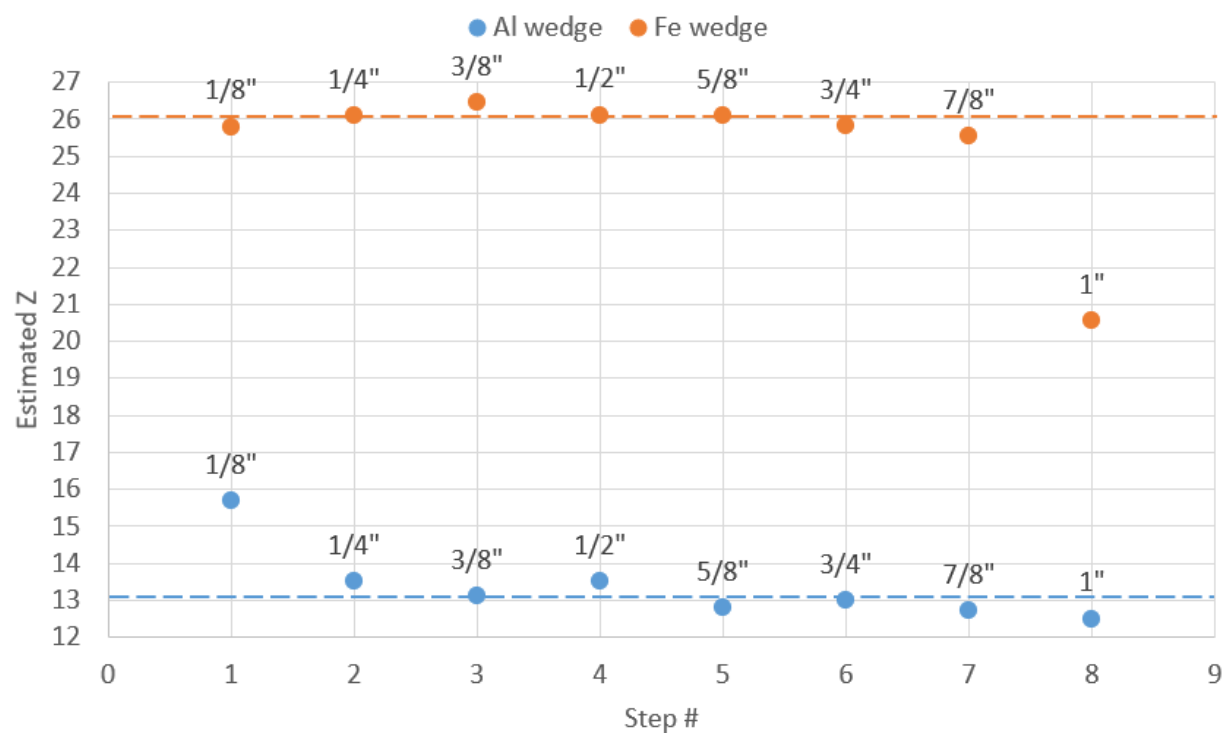

Figure 10. Estimated effective atomic numbers for aluminum (Al) and steel $(\mathrm{Fe})$ when using free parameters.

\section{Summary}

Two approaches proposed by Maitrejean et al. and Osipov et al. were adopted to build numerical algorithms to identify materials based on X-ray absorptiometry. The newly developed algorithms were applied to X-ray DR data obtained from DRCT systems. Maitrejean et al.'s approach was less satisfactory to identify aluminum and steel because $\frac{a_{3}}{a_{1}}$ ratio values were not sensitive enough to distinguish between the different materials. Unlike the original approach by Maitrejean et al. that used X-ray spectrum of up to $150 \mathrm{keV}$, a DRCT system's X-ray energy of up to $300 \mathrm{keV}$ is mostly dominated by photoelectric effect and incoherent scattering, making the contribution from the third basis function (analogous to coherent scattering) insignificant. Osipov et al.'s approach is more straightforward and easier to implement as a numerical algorithm than Maitrejean et al.'s. However, the estimated $\hat{Z}$ values for aluminum and steel need to be more accurate. A semi-empirical formula given by Equation (10) was introduced to improve accuracy of the estimated $\hat{Z}$ values. New data sets from various materials using DRCT systems and extension of the approaches to computed tomography (CT) data are expected to improve performance in the future.

\section{Acknowledgement}

DRCT research and development at Idaho National Laboratory is supported by the U.S. Army Recovered Chemical Materiel Directorate under U.S. Department of Energy Field Office, Idaho contract number DE-AC07-05ID14517. 


\section{References}

[1] Maitrejean, S., Perion, D., \& Sundermann, D. (1998, July). Nondestructive chemical identification using an X-ray transmission function obtained with the multi-energy method. In SPIE's

International Symposium on Optical Science, Engineering, and Instrumentation (pp. 134-152).

International Society for Optics and Photonics.

[2] Osipov, S.P., Udod, V.A., and Wang, Y., Identification of materials in X-ray inspections of objects by the dual energy method, Russ. J. Nondestr. Test., 2017, vol. 53, no. 8, pp. 568-587.

[3] Jolliffe IT, Cadima, J. 2016 Principal component analysis: a review and recent developments, Phil. Trans. R. Soc. A 374: 20150202.

[4] Berger, M.J., Hubbell, J.H., Seltzer, S.M., Chang, J., Coursey, J.S., Sukumar, R., Zucker, D.S., and Olsen, K. (2010), XCOM: Photon Cross Section Database (version 1.5). 
Page intentionally left blank 


\section{Appendix A \\ EXCEL Spreadsheet for Parameter Optimization}


Page intentionally left blank 


\section{Appendix A. EXCEL spreadsheet for parameter optimization}

Figure 11 shows an EXCEL spreadsheet written to find optimal coefficients $\left\{a_{1}, a_{2}, a_{3}\right\}$ for Maitrejean et al.'s approach. Item (1) describes normalized effective X-ray spectra $\phi\left(E, E_{k}\right)$, numbers in item (2) are $d_{k}(H)$ values from the measurements, item (3) corresponds to three basis functions, item (4) corresponds to $\sum_{i} a_{i} \boldsymbol{u}_{\boldsymbol{i}}$ with the coefficients given in item (7), item (5) corresponds to $\exp \left(-\sum_{i} a_{i} \boldsymbol{u}_{i}\right)$, item (6) corresponds to $\hat{d}_{k}(H)$ values calculated by Equation (6), item (7) corresponds to a set of coefficients $\left\{a_{1}, a_{2}, a_{3}\right\}$ to be found, and item (8) is the SSR for a given mass thickness to be minimized by EXCEL Solver.

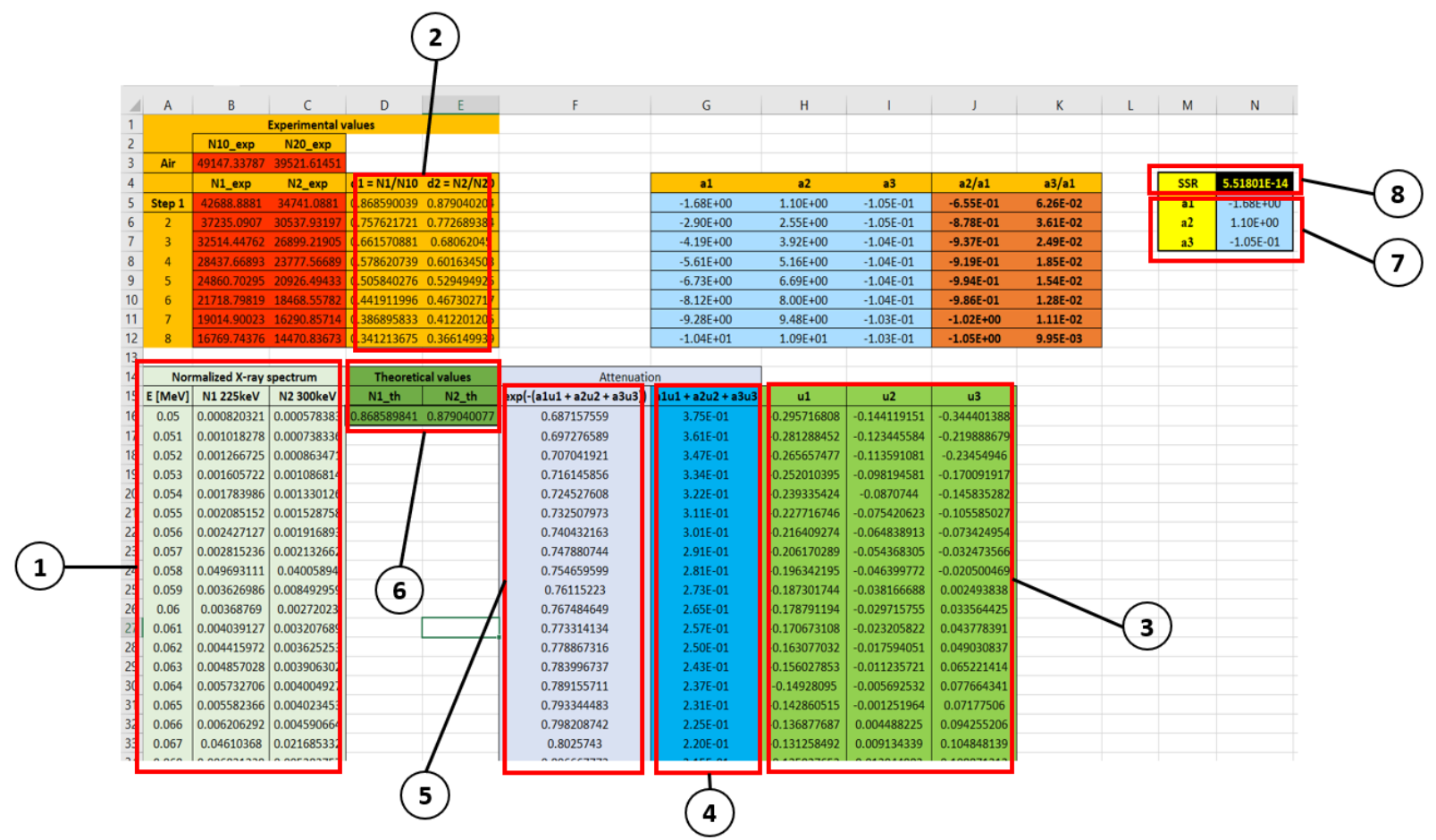

Figure 11. EXCEL spreadsheet for Maitrejean el al.'s approach 
Figure A2 shows an EXCEL spreadsheet written to find optimal coefficients $\{B, D\}$ for Osipov et al.'s approach. Item (1) describes normalized effective X-ray spectra $\phi\left(E, E_{k}\right)$, numbers in item (2) are $d_{k}(H)$ values from the measurements, item (3) corresponds to $B f_{p h}(E)+D f_{K N}(E)$ with the coefficients given in item (6), item (4) corresponds to $\exp \left(-B f_{p h}(E)-D f_{K N}(E)\right)$, item (5) corresponds to $\hat{d}_{k}(H)$ values calculated by Equation (7), item (6) corresponds to a set of coefficients $\{B, D\}$ to be found, and item (7) is the SSR for a given mass thickness to be minimized by EXCEL Solver.

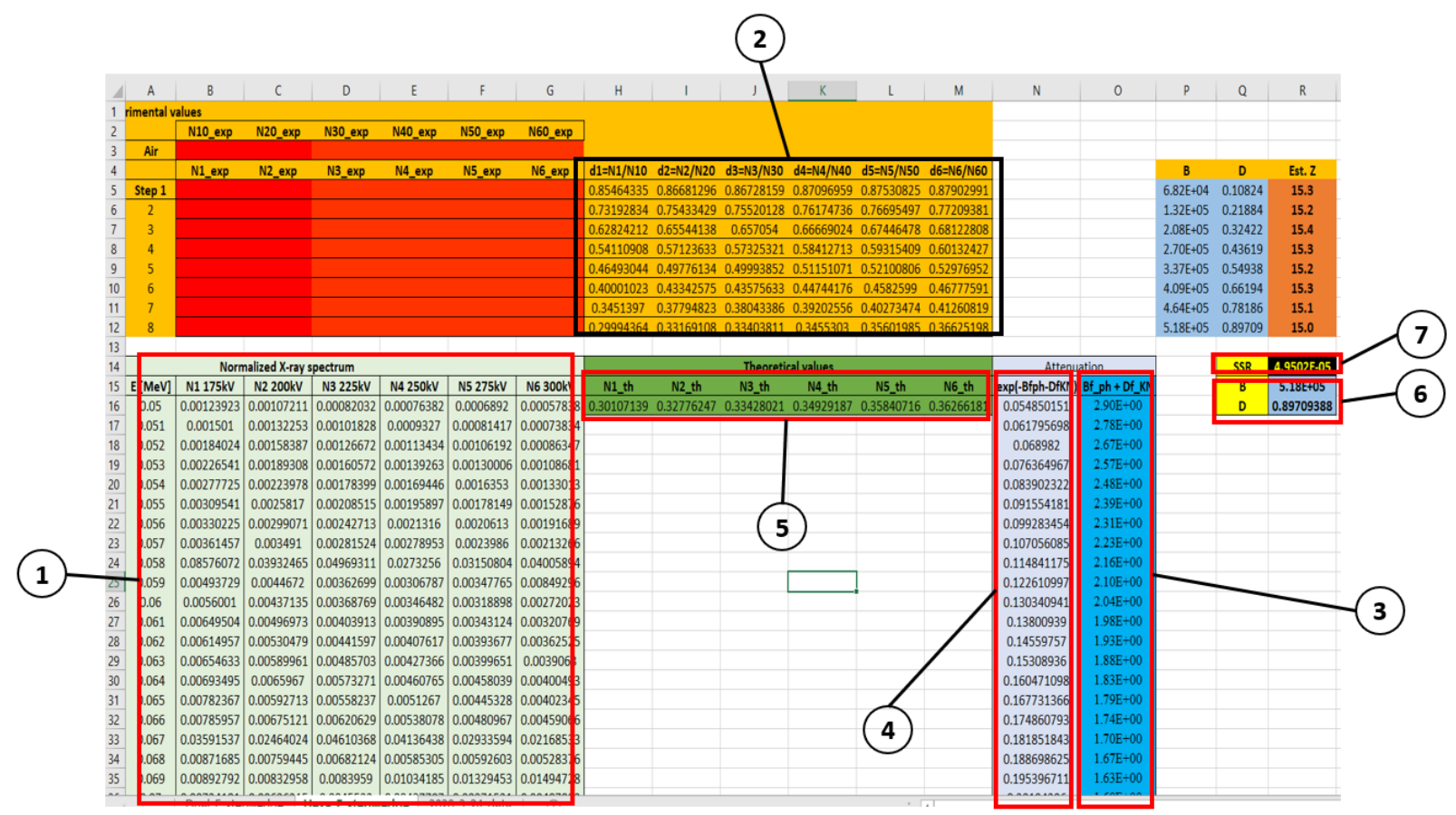

Figure 12. EXCEL spreadsheet for Osipov el al.’s approach. 
Figure A3 shows the Solver parameters setting window. Item (1) points to the cell to be minimized, i.e. SSR value. Item (2) must be checked for "Min" to find parameters that minimizes the goal in item (1). Item (3) points to parameters to be found by minimizing the goal in item (1). Any constraints for the parameters can be set in item (4). Item (5) is unchecked unless the unconstrained parameters need be positive values. Item (6) is set to GRG nonlinear by default for this study. Item (7) starts parameter optimization process by GRG nonlinear method (item (6) to find a set of coefficients (item (3)) that minimizes the cell value (SSR) (item (1)) while meeting the constraints (item (4)).

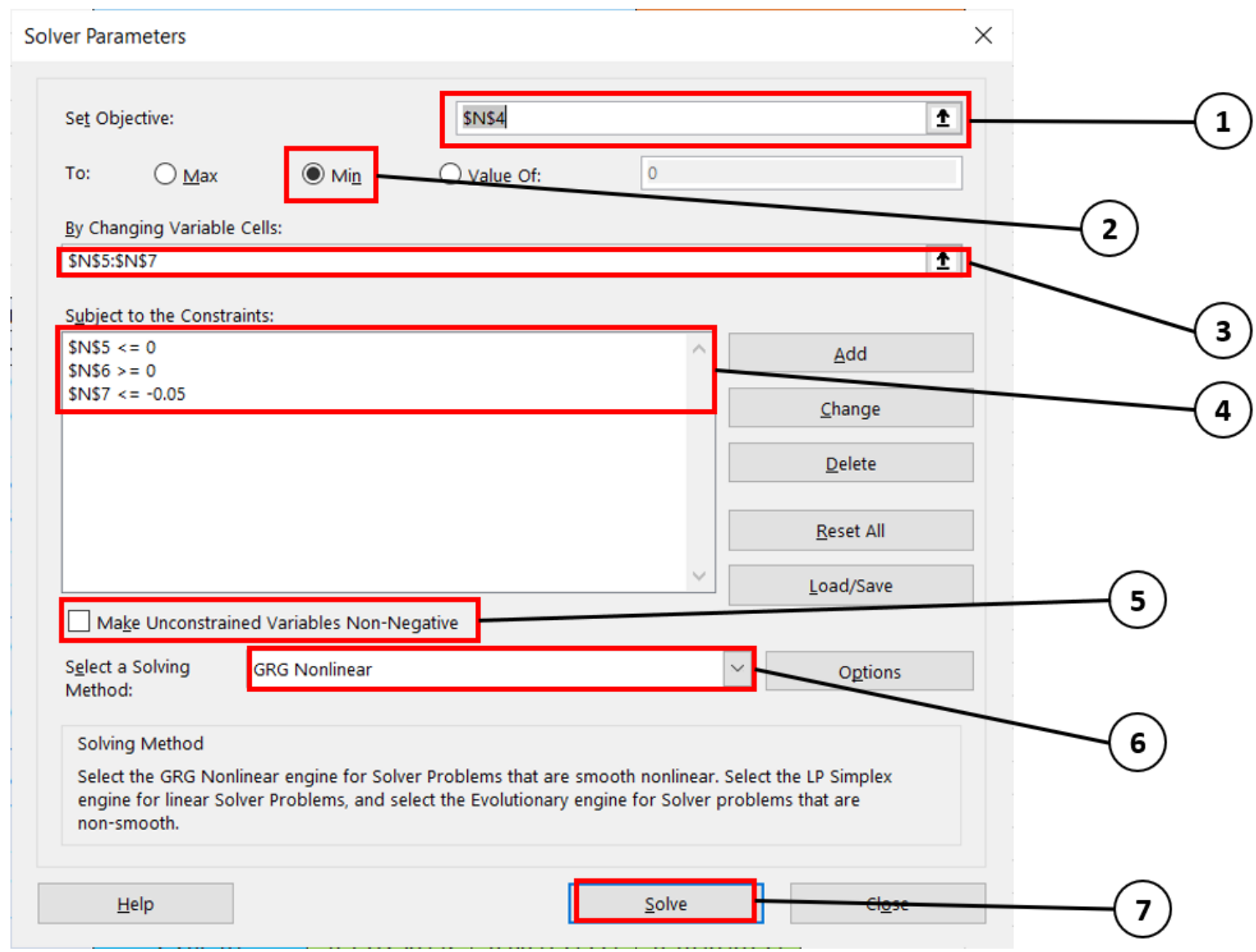

Figure 13. EXCEL Solver parameters window. 